\title{
FRIEDEL-CRAFTS ACYLATION OF ARSABENZENE
}

Arthur J. Ashe, III,* Woon-Tung Chan and Timothy W. Smith

Department of Chemistry, The University of Michigan, Ann Arbor, Michigan 48109

(Received in USA 22 March 1978; received in UK for publication 25 May 1978)

Spectroscopic measurements indicate that arsabenzene 1 , the arsenic analog of pyridine, displays a high degree of aromatic character. 1 Thus $1_{\mathrm{H}-\mathrm{nmr}}$ spectrum shows that arsabenzene possesses a diamagnetic ring current. ${ }^{2}$ Gas phase structural data indicate a planar ring with aromatic $\mathrm{C}-\mathrm{C}$ bond distances of $1.395 \AA^{3}$ UV photoelectron spectra ${ }^{4}$ supported by various MO studies, 4,5 are in accord with this aromaticity. However, the chemical demonstration of the aromaticity has been more modest, 6,7 and in particular no electrophilic aromatic substitution reactions have previously been reported. ${ }^{7}$ We now wish to report that arsabenzene will undergo facile Friedel Crafts acylation.

Acetylation of arsabenzene at $-70^{\circ}$ in $\mathrm{CH}_{2} \mathrm{Cl}_{2}$ with $\mathrm{CH}_{3} \mathrm{COCl}-\mathrm{AlCl}_{3}$ gave up to $80 \%$ isolated yield of monoacetylarsabenzenes. Although we have been unable to separate this mixture using a variety of g.1.p.c. columns, the $1_{\mathrm{H}-\mathrm{nmr}}$ spectrum showed two acyl methyl groups $\left(\delta\left(\mathrm{C}_{6} \mathrm{D}_{6}\right) 2.13,2.37\right)$ in the ratio of $4: 1$. However, the simple ${ }^{1} \mathrm{H}$-nmr spectrum of the major isomer established that it was 4-acetylarsabenzene $\underline{2}^{8}{ }^{8} 1_{\mathrm{H}-\mathrm{nmr}}\left(\delta\left(\mathrm{C}_{6} \mathrm{D}_{6}\right) 2.13(3 \mathrm{H}, \mathrm{s})\right.$; $8.22(2 \mathrm{H}, \mathrm{d}, \mathrm{J}=10 \mathrm{~Hz}), 9.38(2 \mathrm{H}, \mathrm{d}, \mathrm{J}=10 \mathrm{~Hz})$. Similarly the nur spectrum of the mixture suggested that the minor component was the 2 -isomer $\underline{3}$.

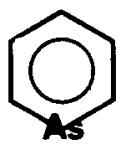

$\underline{1}$

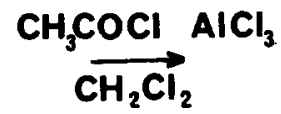

$-70^{\circ}$

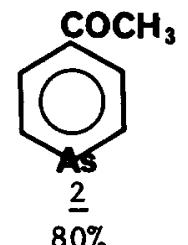

$80 \%$

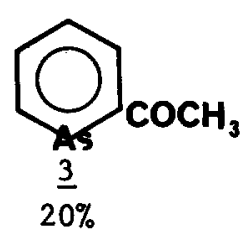


For comparison, authentic samples of the 2- and 3-acetylarsabenzenes were synthesized by a modification of our Diels-Alder synthesis. 9 The reaction of arsabenzene with ethynyl methyl ketone gave a mixture of adducts 4 and 5 in the ratio of $2: 3$. Treating the unseparated mixture with the acetylene abstraction agent, 3,6-di( $\alpha$-pyridyl)-1,2,4,5-tetrazine, ${ }^{10}$ at $25^{\circ}$ afforded near quantitative conversion to 2 - and 3 -acetylarsabenzenes $\underline{3}$ and $\underline{6}$. After separation by g.1.p.c., they showed the following ${ }_{\mathrm{H} \text {-nmr spectra: }}$ For $\underline{3}: \quad \delta\left(\mathrm{C}_{6} \mathrm{D}_{6}\right) 2.37(3 \mathrm{H}, \mathrm{s}), 7.2-7.7(2 \mathrm{H}, \mathrm{m}), 8.3(1 \mathrm{H}, \mathrm{d}, \mathrm{J}=8 \mathrm{~Hz}, 9.48(1 \mathrm{H}, \mathrm{d}, \mathrm{J}=9 \mathrm{~Hz})$; and for $\underline{6}: \quad\left(\delta\left(\mathrm{C}_{6} \mathrm{D}_{6}\right) 2.12(3 \mathrm{H}, \mathrm{s}), 7.35-8.1(2 \mathrm{H}, \mathrm{m}) 9.52(1 \mathrm{H}, \mathrm{d}, \mathrm{J}=10 \mathrm{~Hz}), 10.0(1 \mathrm{H}, \mathrm{s})\right.$ Comparison proved that 2-acetylarsabenzene was the minor acetylation product. However, the 3-isomer which is stable under the acylation conditions is not present in the product down to the estimated level of detection of $0.5 \%{ }^{11}$ This allows the partial rate factors for the different positions of arsabenzene to be estimated: $k_{\alpha}: k_{B}: k_{\gamma}=40:(<1): 300$.
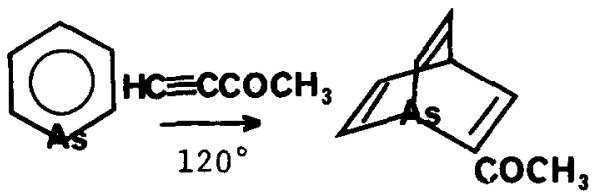
$\frac{4}{40 \%}$

$\mathbf{N}_{2}$

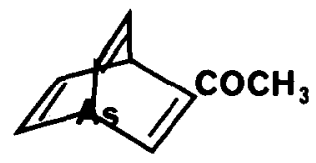

$\underline{5}$ $60 \%$

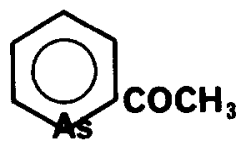

$\underline{3}$
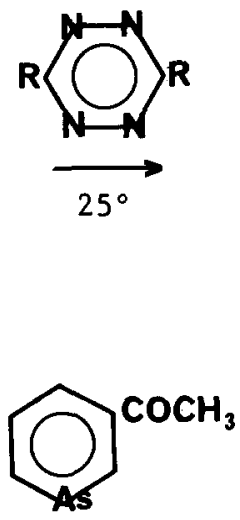

$\underline{6}$

When the most reactive $\gamma$-position is blocked, substitution takes place at the $\alpha$-position. Thus 4-methylarsabenzene ${ }^{12}$ gave a $50 \%$ isolated yield of

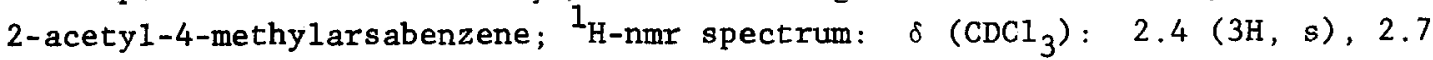
$(3 \mathrm{H}, \mathrm{s}), 7.78(1 \mathrm{H}, \mathrm{d}, \mathrm{J}=10 \mathrm{~Hz}), 8.27(1 \mathrm{H}, \mathrm{s}), 9.67(1 \mathrm{H}, \mathrm{d}, \mathrm{J}=10 \mathrm{~Hz})$. However, in contrast to the results on the parent system, moderate amounts of an intractable arsenic containing tar were obtained.

The reactivity of arsabenzene can be compared with that of the more familiar benzocyclic aromatics by competition experiments. Mesitylene is acetylated half as fast as arsabenzene. Correcting for the statistical factor of three the $\gamma$-position of arsabenzene is six times more reactive than mesitylene and approximately $10^{4}$ times more reactive than benzene. ${ }^{12}$

Qualitatively, the effect of the electropositive heteroatom of arsabenzene appears to be comparable to that of an activating ortho-para directing 
group on a benzene ring. ${ }^{14}$ Presumably as in the benzocyclic case, only electrophilic attack at the para-1ike $(\gamma)$ or ortho-like ( $\alpha$ ) positions allows efficient electronic interaction in the intermediate $\sigma$-complex 7 . Perhaps the relatively greater reactivity of $\gamma$ - over the $\alpha$-position can be explained by noting that the HOMO of arsabenzene with a $B_{1}$ symmetry ${ }^{4}$ has a larger coefficient for $\gamma$ - than for $\alpha$-carbon. Thus interaction with the incoming electrophile might be more effective at the $\gamma$-position. ${ }^{15}$

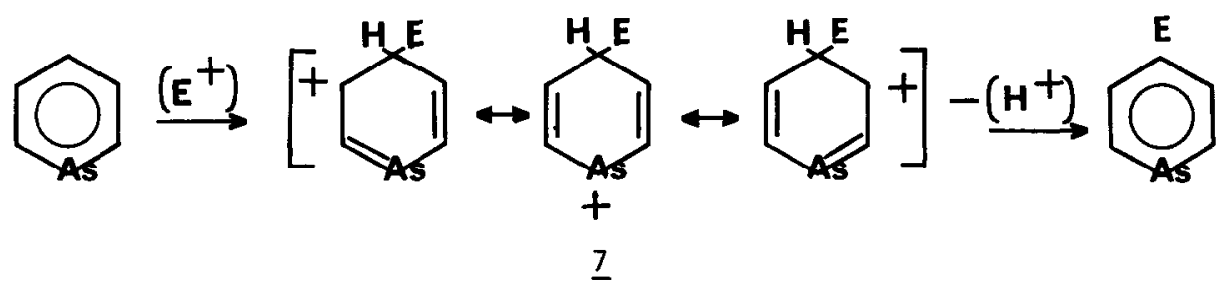

We are continuing our investigation of other electrophilic substitution reactions. Preliminary results, which will be communicated elsewhere in detail, Indicate that arsabenzene will undergo acid catalyzed deuterium exchange, while trimethylsilylarsabenzenes undergo protodesilylation.

Acknolwedgment. Partial support for this work by the National Science Foundation (Grant No. MPS74-17594) and the National Institutes of Health (Grant No. R01-GM20992) is gratefully acknowledged.

\section{Footnotes and References}

1. A. J. Ashe, III, Acc. Chem. Res., 11, in press (1978).

2. A. J. Ashe, III, R. R. Sharp and J. W. Tolan, J. Amer. Chem. Soc., 98, 5451 (1976).

3. T. C. Wong, A. J. Ashe, III and L. S. Bartell, J. Mo1. Struct., 25, 65 (1975); R. P. Lattimer, R. L. Kuczkowski, A. J. Ashe, III and A. L. Meinzer, J. Mol. Syectrosc., 57, 428 (1975).

4. C. Batich, E. Hellbronner, V. Hornung, A. J. Ashe, III, D. T. Clark, U. T. Cobley, D. Kilcast and I. Scanlan, J. Amer. Chem. Soc., 95, 928 (1973); A. J. Ashe, III, F. Burger, M. Y. El-Sheik, E. Heilbronner, J. P. Maier and J.-F. Muller, Helv. Chim. Acta, 59, 1944 (1976).

5. D. T. Clark and I. W. Scanlan, J. Chem. Soc., Farad. Trans. II, 70, 1222 (1974); H. Oehling and A. Schweig, Tetrahedron Lett., 4941 (1970).

6. For example, allyl arsabenzene ether undergoes Claisen rearrangement: G. Maerk1 and J. B. Rampal, Angew. Chem. Int. Ed. Engl. , 15, 690 (1976).

7. However, the fragmentation-rearrangement of 1-ary1-4-methoxy-arsacyc1ohexadiene might be thought of as an electrophilic aromatic substitution 
reaction. See: G. Maerk1 and R. Lieb, Angew. Chem. Int. Ed. Eng1., 16, 637 (1977).

8. When the acetylation was carried out at $-30^{\circ}$, compound $\underline{2}$ was isolated pure in lower yield. Compound 3 , which is stable under the reaction conditions, was no longer detected. Whether the intermediate $\sigma$-complex leading to $\underline{2}$ was preferentially destroyed or was converted to $\underline{7}$ at the higher temperature has not yet been determined.

9. A. J. Ashe, III and H. S. Friedman, Tetrahedron Lett., 1283 (1977).

10. We thank Dr. Warrener for suggesting this modification. See: R. N. Warrener, J. Amer. Chem. Soc., 93, 2346 (1971).

11. The analysis was performed on Varian Aerograph Model 2440 Gas Chromatograph equipped with flame ionization detector (Column: 3\% OV-101 on $80 / 100$ varaport $30,1 / 8^{\prime \prime} \times 5^{\prime}$ ). At $105 \frac{1}{4}$ and $60 \mathrm{psi}$, authentic samples of $\underline{6}$ and $\underline{2}$ had retention times 15 and 16 minutes respectively ( $\underline{2}$ and $\underline{3}$ were unresolved). The acetylation product showed only the 16-minute peak.

12. A. J. Ashe, III and W. T. Chan, Tetrahedron Lett., 2749 (1975).

13. Under slightly different conditions the relative rates of acetylation of benzene:mesitylene are $1: 2.9 \times 10^{3}$. G. Marino and H. C. Brown, J. Amer. Chem. Soc., 81, 5929 (1959).

14. In the same manner the electronegative heteroatom of pyridine might be compared to the effect of a deactivating meta-directing group on benzene.

15. K. Fukui, T. Yonezawa, C. Nagata and H. Shingu, J. Chem. Phys., 22, 1433 (1954). 